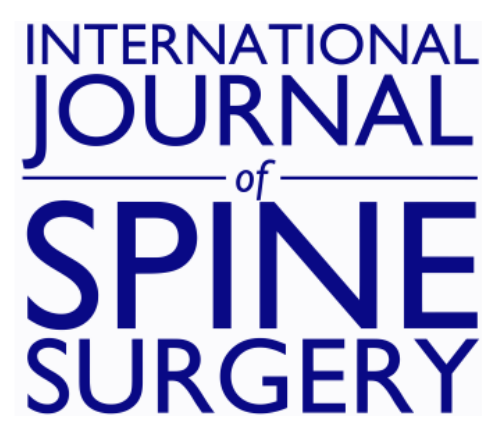

\title{
Risk Factors for Accidental Dural Tears in Spinal Surgery
}

Zeiad A.F. Alshameeri and Vinay Jasani

Int J Spine Surg 2021, 15 (3) 536-548

doi: https://doi.org/10.14444/8082

http://ijssurgery.com/content/15/3/536

This information is current as of April 26, 2023.

Email Alerts Receive free email-alerts when new articles cite this article. Sign up at: http://ijssurgery.com/alerts 


\title{
Risk Factors for Accidental Dural Tears in Spinal Surgery
}

\author{
ZEIAD A.F. ALSHAMEERI, FRCS, VINAY JASANI, FRCS \\ University Hospital of North Midlands, Royal Stoke University Hospital, Stoke-on-Trent, United Kingdom
}

\begin{abstract}
Background: Accidental dural tears (DTs) are familiar complications of spinal surgery. Their reported incidence varies widely, and several risk factors have been proposed in the literature. The aim of this study was to conduct a systematic review and meta-analysis to determine the rate of DTs and assess their associated risk factors.

Methods: A systematic literature search was conducted using specific MeSH and Text terms. Only articles with prospective data reporting the incidence and risk factors were selected and reviewed based on specific inclusion and exclusion criteria.

Results: Twenty-three studies were included. The reported incidence rate ranged from $0.4 \%$ to $15.8 \%$, giving an overall pooled incidence rate of 5.8\% (95\% confidence interval [CI] 4.4-7.3). The incidence rate varied in relation to the part of the spine and the type of surgery. Three factors were associated with a high rate of DTs: age (overall mean difference of 3.04, 95\% CI 2.49-3.60), revision surgery (overall odds ratio of 2.28, 95\% CI 1.84-2.83), and lumbar stenosis (overall odds ratio of $2.03,95 \%$ CI 1.50-2.75). Diabetes was weakly associated with DTs, with an odds ratio of 1.40 (95\% CI 1.01-1.93). The overall effects of sex and obesity were not statistically significant.

Conclusion: Advancing age, revision surgery, and lumbar stenosis were significantly associated with increased risk of DTs. These factors should be taken into consideration during the consenting process for spinal surgery.

Clinical Relevance: Risk of dural tear during spine surgery.
\end{abstract}

Complications

Keywords: accidental dural tear, incidental dural tear, durotomy, spinal surgery, risk factors

\section{INTRODUCTION}

Accidental dural tears (DTs) are familiar complications of spinal surgery. They have been associated with neurological injuries ${ }^{1}$ and poor outcome in some studies. ${ }^{2}$ The reported incidence of DTs varied widely in the literature, ${ }^{3}$ and several risk factors have been proposed..$^{3-6}$ Revision surgery is a risk factor that has been associated with DTs, ${ }^{5-8}$ but the associations of other factors, such as sex, diabetes, and age, with DTs have not been consistent in the literature. ${ }^{5,7}$ One reason for this could be the retrospective nature of many of the current published studies that are potentially blighted by bias, affecting the accuracy of the reported rates of DTs and their associated risk factors.

Therefore, the aim of this study was to carry out a systematic review of the literature to conduct a quantitative meta-analysis on the rate of DTs and their associated risk factors in elective spinal surgery. Only studies with prospectively collected data were included in this meta-analysis, and the following commonly reported risk factors were assessed: revision surgery, diagnosis (lumbar stenosis and lumbar disc herniation), age, sex, body mass index (BMI), and diabetes.

\section{METHODS}

A systematic literature search was conducted as part of a comprehensive project looking at the treatment and outcome of DTs in elective spinal surgery. 9,10 The method of the systematic literature search and $\mathrm{MeSH}$ terms used were reported in previous publications. ${ }^{9,10}$ Briefly, this was conducted in Embase, Cochrane, Medline, and PubMed from inception until the end of January 2019. The identification and selection process of the studies followed the PRISMA flow chart (Figure 1). The details of all identified titles were downloaded into an Excel spread sheet, which facilitated the exclusion of duplicates, foreign language, case reports, and conference abstracts. The remaining titles and abstracts were reviewed, and any article that included any reference to incidental (iatrogenic or accidental) DTs (or ambiguous articles) was initially selected for further review. Full manuscripts for the 


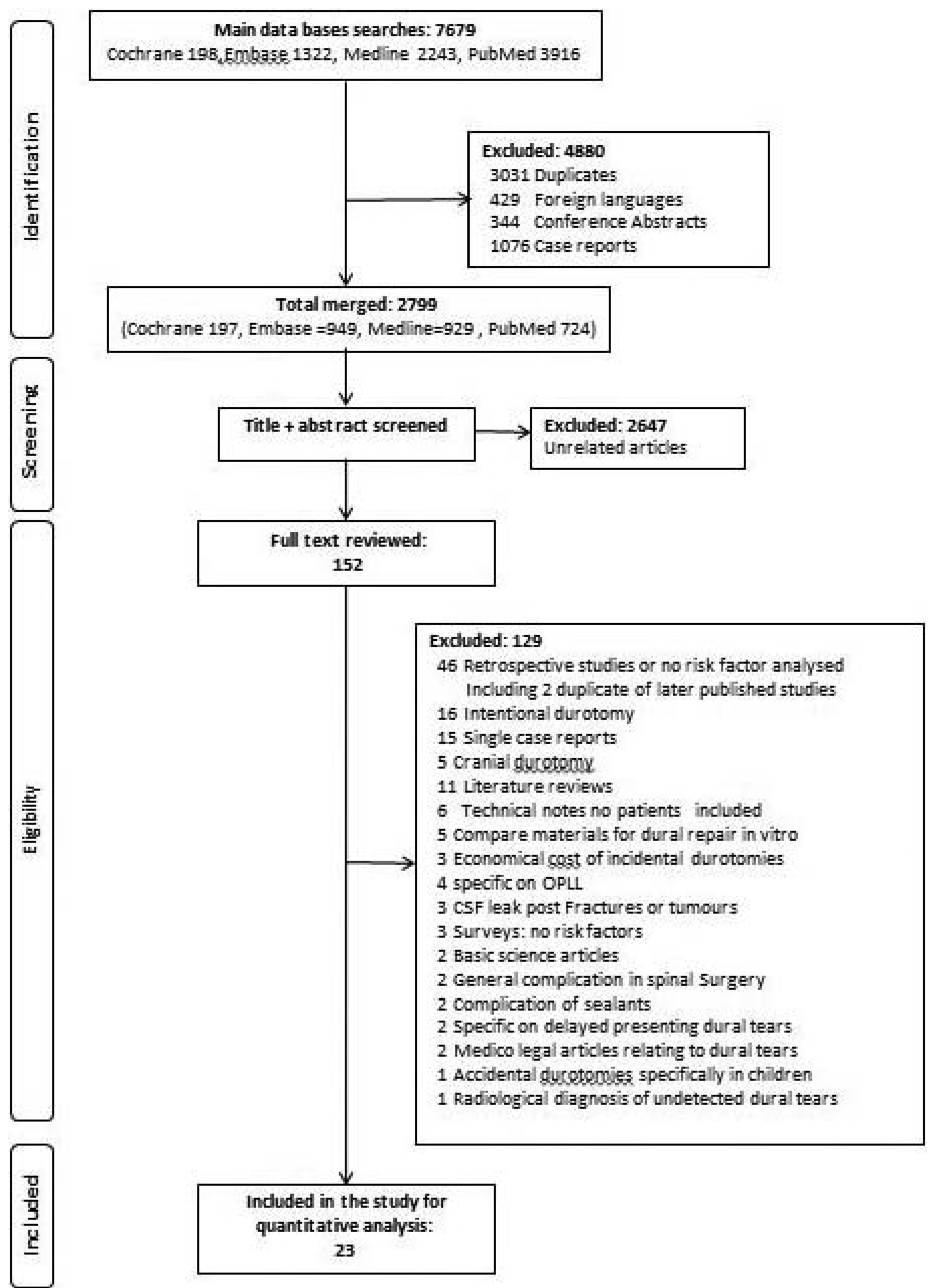

Figure 1. PRISMA flow chart demonstrating the selection process of the studies on risk factors for dural tears in spinal surgery. CSF, cerebrospinal fluid leak; OPLL, ossification of the posterior longitudinal ligament.

selected articles were then retrieved and reviewed for final inclusion. An up-to-date search covering the period from January 2019 to January 2020 was conducted, but none of the new articles met the inclusion criteria for this meta-analysis.

\section{Assessing Study Eligibility}

Only studies with prospective collection of the original data (especially patients' baseline characteristics) were included. Studies with retrospective 
Table 1. Inclusion and exclusion criteria.

\section{Inclusion Criteria}

1. Articles on unintended (incidental, accidental, iatrogenic) dural tears (DTs) in elective spinal surgery in adults.

2. Prospective collection of original data.

3. The study has to mention and compare the frequency of incidental DTs in their cohort of patients with at least one of the following risk factors: age, revision (reoperation) surgery, diagnosis (lumbar disc herniation and lumbar stenosis), sex, and body mass index (BMI) (obesity).

4. English language articles.

5. Human participants.

6. Case series, case control, cohort, and randomized control trials were eligible to be included if they fulfilled the above criteria.

Exclusion Criteria

1. Studies with retrospective collection of baseline data or those that did not mention the time of data collection.

2. Individual case reports, abstracts, and articles in languages other than English.

3. Articles specifically dealing with ossification of the posterior longitudinal ligament.

4. Studies based on data from insurance companies' databases.

5. Dural tears from fractures, tumors, or intentional durotomies.

analysis of prospectively collected data, such as nested case control studies (from prospective cohort studies) or studies based on national registries or hospital databases with prospectively collected data, were also included. The inclusion and exclusion criteria are shown in Table 1.

\section{Assessing Study Quality}

The types and quality scores of each study identified are presented in Table 2. Most were nonrandomized control trials, and the NewcastleOttawa quality assessment scale ${ }^{31}$ was used to assess the quality. This particular scale awards different numbers of stars based on three different categories: selection (maximum 4 stars), comparability (maximum 2 stars), and outcome (maximum 3 stars). This scale awards 1 star for controlling for factors during comparability, and therefore a star was awarded for multivariate analysis on multiple factors. Patients' responses and follow-up were irrelevant in this situation because all of the risk factors were based on patients' baseline characteristics. Therefore, the outcome score was awarded based on the original aim of each study.

\section{Extraction of the Data}

Data extraction was done according to a predetermined pro forma. Information on the type of study, the data source, the type and size of the cohort, and the risk factors covered were gathered and are presented in Tables 2 and 3.
The type of data extracted depended on the risk factor. Most articles with data on age reported the mean, the standard deviation (SD), and the sample size for patients with and without DTs. Hence, for the few articles that presented data on age but lacked some of these details, the authors were contacted to provide the mean and SD for their cohorts. When authors did not respond, the articles with missing details were excluded.

Articles with data on BMI reported their data as either categorical or continuous (mean and SD). For articles with categorical data, the cohorts were divided into two categories (BMI $>30$ and BMI $<30$ ) in accordance with the World Health Organization's definition of obesity, ${ }^{32}$ and the overall odds ratio of DTs in obese patients was calculated. For articles with continuous data, the mean difference in BMI was calculated.

For the rest of the risk factors (diagnosis, revision surgery, diabetes, and sex), the number of patients with each risk factor in both cohorts (DTs and no DTs) was extracted from all articles that contained data on these risk factors. There were 3 separate studies from the SPORT trials all reporting the outcome of incidental DTs in disc herniation (discectomy), ${ }^{14}$ lumbar stenosis, ${ }^{23}$ and spondylolisthesis. ${ }^{17}$ The data from two studies ${ }^{14,23}$ were directly compared in the meta-analysis.

\section{Data Synthesis}

Meta-analysis calculations were conducted using the Review Manager 5 software (Cochrane collaboration).

For age and BMI (continuous data), the pooled weighted mean difference was calculated using the inverse variance and the random effect model. For categorical data (BMI, sex, revision, and diabetes), we calculated the overall weighted odds ratios based on the actual number of patients with and without DTs. The inverse variance and random effect model was also used to calculate the weighted difference and pooling of the overall odds ratio.

We examined heterogeneity using tau-squared and $\chi^{2}$ tests. The $I^{2}$ statistic was used as an estimate for the total variation across studies owing to heterogeneity. To assess publication bias and outliers, a funnel plot was plotted for each risk factor.

The overall risk of DTs and the risk of DTs in different regions of the spine or in association with each factor was calculated using meta-analysis of 


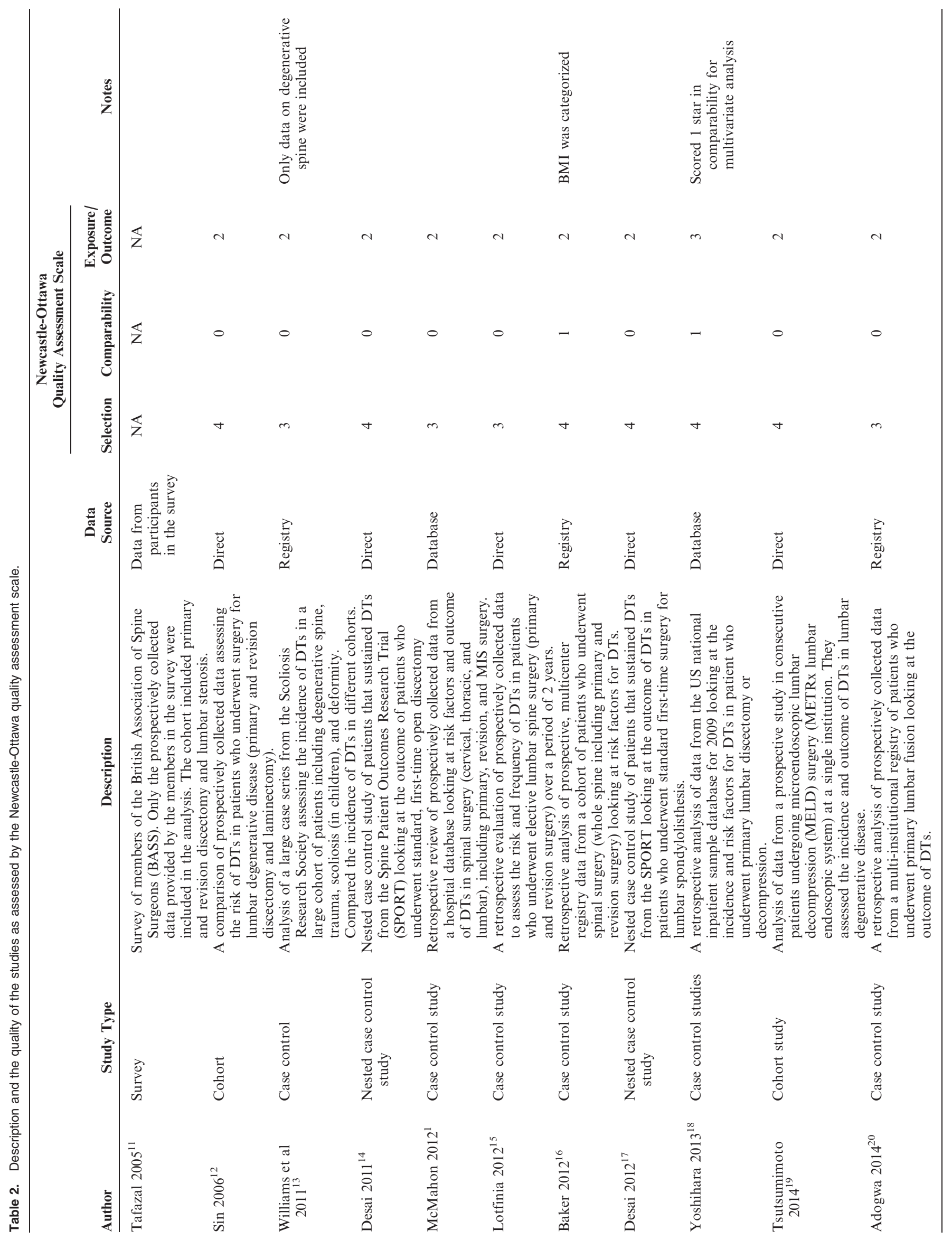




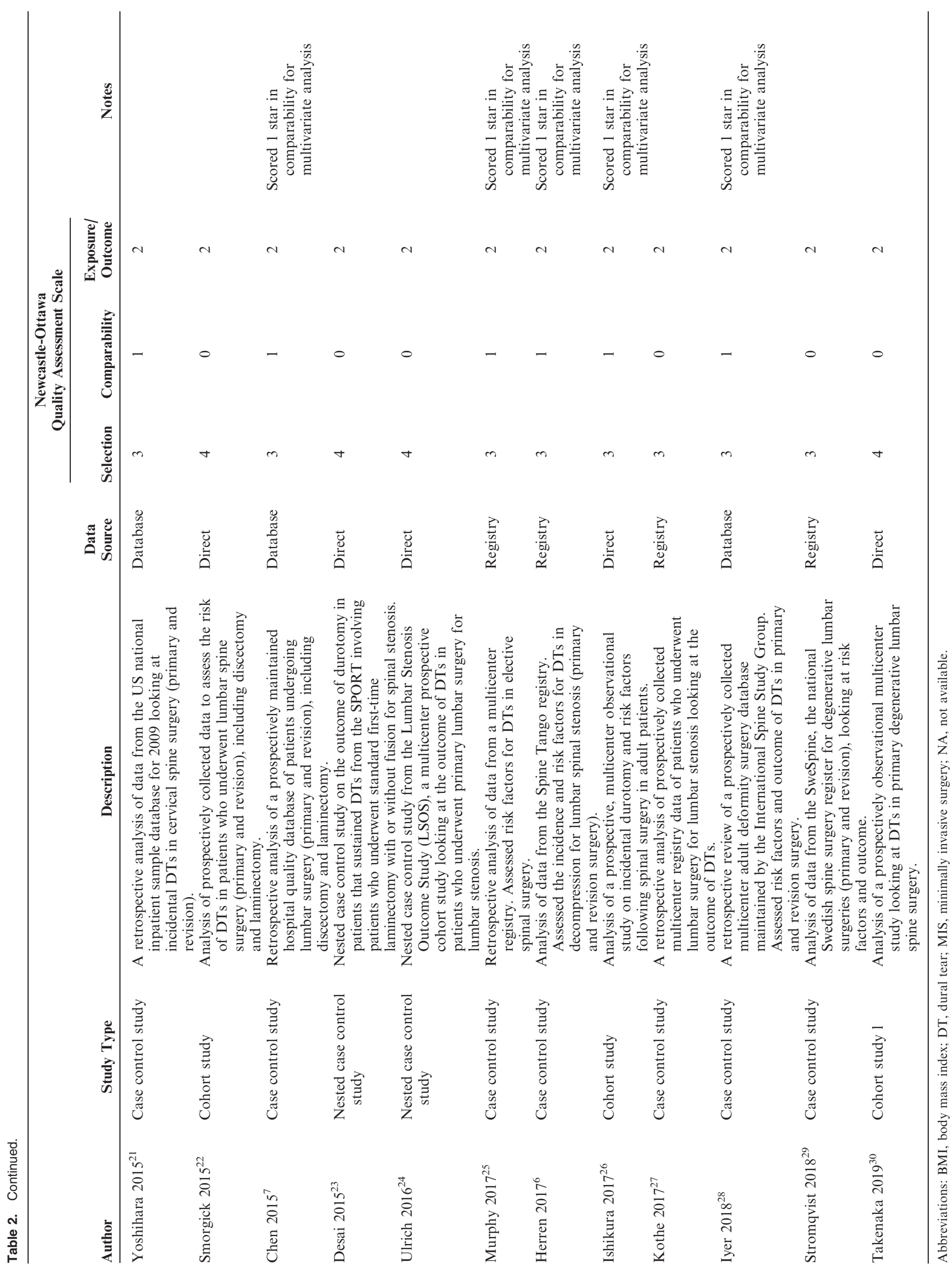


Table 3. Incidence of accidental dural tears and risk factors in each study included.

\begin{tabular}{|c|c|c|c|c|c|c|c|c|c|c|c|}
\hline \multirow[b]{2}{*}{ Author } & \multirow{2}{*}{$\begin{array}{l}\text { Part of } \\
\text { Spine }\end{array}$} & \multirow[b]{2}{*}{ Surgery } & \multirow{2}{*}{$\begin{array}{c}N \\
\text { Total } \\
\text { Cohort }\end{array}$} & \multirow{2}{*}{$\begin{array}{l}N(\%) \\
\text { Dural } \\
\text { Tears }\end{array}$} & \multicolumn{6}{|c|}{$\begin{array}{l}\text { Available Data on Risk } \\
\text { Factors for Meta-Analysis }\end{array}$} & \multirow[b]{2}{*}{ Notes } \\
\hline & & & & & Age & Sex & Diagnosis & Revision & Diabetes & BMI & \\
\hline Tafazal $2005^{11}$ & Lumbar & $\begin{array}{l}\text { Primary and } \\
\text { revision }\end{array}$ & 1549 & $93(6.0)$ & No & No & Yes & Yes & No & No & $\begin{array}{l}\text { Only prospectively collected } \\
\text { data from the survey } \\
\text { were used for this } \\
\text { analysis. }\end{array}$ \\
\hline $\operatorname{Sin} 2006^{12}$ & Lumbar & $\begin{array}{l}\text { Primary and } \\
\text { revision }\end{array}$ & 76 & $12(15.8)$ & Yes & No & No & No & No & No & \\
\hline Williams $2011^{13}$ & Whole & $\begin{array}{l}\text { Primary and } \\
\text { revision }\end{array}$ & 47399 & $852(1.8)$ & No & No & Yes & No & No & No & $\begin{array}{l}\text { Only data on degenerative } \\
\text { spine were included. }\end{array}$ \\
\hline Desai $2011^{14}$ & Lumbar & Primary & 799 & $25(3.1)$ & Yes & Yes & Yes & No & Yes & Yes & $\begin{array}{l}\text { The diagnosis from this } \\
\text { study was compared with } \\
\text { Desai } 2015^{23} \text {. }\end{array}$ \\
\hline McMahon $2012^{1}$ & Whole & $\begin{array}{l}\text { Primary and } \\
\text { revision }\end{array}$ & 3000 & $104(3.5)$ & No & No & No & Yes & No & No & \\
\hline Lotfinia $2012^{15}$ & Lumbar & $\begin{array}{l}\text { Primary and } \\
\text { revision }\end{array}$ & 1116 & $92(8.2)$ & No & No & No & Yes & No & No & \\
\hline Baker $2012^{16}$ & Whole & $\begin{array}{l}\text { Primary and } \\
\text { revision }\end{array}$ & 1591 & $161(10.1)$ & Yes & Yes & No & Yes & Yes & Yes & BMI was categorized. \\
\hline Desai $2012^{17}$ & Lumbar & Primary & 389 & $41(10.5)$ & Yes & Yes & No & No & Yes & Yes & \\
\hline Yoshihara $2013^{18}$ & Lumbar & Primary & 204464 & $6819(3.3)$ & Yes & Yes & Yes & No & Yes & Yes & $\begin{array}{l}\text { Only data for diabetes were } \\
\text { used from this study. } \\
\text { Data for other risk } \\
\text { factors obtained from a } \\
\text { more recent update study } \\
\text { (Yoshihara } 2015^{21} \text { ). }\end{array}$ \\
\hline $\begin{array}{l}\text { Tsutsumimoto } \\
2014^{19}\end{array}$ & Lumbar & $\begin{array}{l}\text { Primary and } \\
\text { revision }\end{array}$ & 555 & $28(5.0)$ & No & Yes & Yes & Yes & No & No & $\begin{array}{l}\text { Could not analyze for age } \\
\text { as only odds ratio and } \\
\text { mean with range were } \\
\text { available, but no SD data } \\
\text { were available. }\end{array}$ \\
\hline Adogwa $2014^{20}$ & Lumbar & Primary & 1741 & $70(4.0)$ & Yes & Yes & No & No & No & Yes & \\
\hline Yoshihara $2015^{21}$ & Cervical & $\begin{array}{l}\text { Primary and } \\
\text { revision }\end{array}$ & 190021 & $855(0.4)$ & Yes & Yes & Yes & Yes & No & Yes & $\begin{array}{l}\text { Age was categorized; } \\
\text { therefore, it was not } \\
\text { included in the analyses. }\end{array}$ \\
\hline Smorgick $2015^{22}$ & Lumbar & $\begin{array}{l}\text { Primary and } \\
\text { revision }\end{array}$ & 523 & $55(10.5)$ & Yes & No & Yes & Yes & No & No & \\
\hline Chen $2015^{7}$ & Lumbar & $\begin{array}{l}\text { Primary and } \\
\text { revision }\end{array}$ & 2184 & $101(4.6)$ & Yes & Yes & Yes & Yes & Yes & Yes & \\
\hline Desai $2015^{23}$ & Lumbar & Primary & 409 & $37(9.0)$ & Yes & Yes & Yes & No & Yes & Yes & $\begin{array}{l}\text { The diagnosis from this } \\
\text { study was compared with } \\
\text { Desai } 2011^{14} \text {. }\end{array}$ \\
\hline Ulrich $2016^{24}$ & Lumbar & Primary & 167 & $15(9.0)$ & No & Yes & No & No & Yes & No & $\begin{array}{l}\text { Only the median and IQR } \\
\text { were presented for age; } \\
\text { therefore, not included in } \\
\text { the analysis. }\end{array}$ \\
\hline Murphy $2017^{25}$ & Whole & $\begin{array}{l}\text { Primary and } \\
\text { revision }\end{array}$ & 104930 & $655(0.6)$ & No & Yes & No & No & Yes & Yes & $\begin{array}{l}\text { BMI data were categorized. } \\
\text { Age was not included } \\
\text { because median and IQR } \\
\text { were presented. }\end{array}$ \\
\hline Herren $2017^{6}$ & Lumbar & $\begin{array}{l}\text { Primary and } \\
\text { revision }\end{array}$ & 3254 & $328(10.1)$ & Yes & Yes & No & Yes & No & Yes & BMI data were categorized. \\
\hline Ishikura $2017^{26}$ & Whole & $\begin{array}{l}\text { Primary and } \\
\text { revision }\end{array}$ & 4652 & $380(8.2)$ & Yes & Yes & Yes & Yes & Yes & Yes & \\
\hline Kothe $2017^{27}$ & Lumbar & $\begin{array}{l}\text { Primary and } \\
\text { revision }\end{array}$ & 800 & $67(8.4)$ & Yes & Yes & No & Yes & No & Yes & \\
\hline Iyer $2018^{28}$ & Whole & $\begin{array}{l}\text { Primary and } \\
\text { revision }\end{array}$ & 564 & $61(10.8)$ & Yes & Yes & No & Yes & No & Yes & \\
\hline Stromqvist $2018^{29}$ & Lumbar & $\begin{array}{l}\text { Primary and } \\
\text { revision }\end{array}$ & 64431 & $3038(4.7)$ & Yes & Yes & Yes & Yes & No & No & $\begin{array}{l}\text { Categorized patients into } 3 \\
\text { groups based on } \\
\text { procedure and presented } \\
\text { the data separately for } \\
\text { each group. }\end{array}$ \\
\hline Takenaka $2019^{30}$ & Lumbar & $\begin{array}{l}\text { Primary and } \\
\text { revision }\end{array}$ & 13188 & $451(3.4)$ & Yes & Yes & Yes & No & No & No & $\begin{array}{l}\text { Authors kindly provided } \\
\text { the SD for the data. }\end{array}$ \\
\hline
\end{tabular}

Abbreviations: BMI, body mass index; IQR, interquartile range; SD, standard deviation. 
proportions $^{33,34}$ using the StatDirect software. The pooled proportions ranged from 0 to 1 , corresponding with $0 \%$ to $100 \%$ respectively.

\section{RESULTS}

Twenty-three studies fulfilled our inclusion criteria $^{1,6,7,11-30}$ (Table 2). The number of studies evaluating different risk factors is presented in Table 3. William et $\mathrm{a}^{13}$ reported a large case series from a registry database that included DTs from fractures and scoliosis in children as well as degenerative spine. Only data relating to the degenerative spine were included.

\section{Quality of the Studies}

The majority $(n=18)$ were case control studies including 4 nested case control studies, 3 from randomized control trials and 1 from a prospective cohort study. One survey contained prospectively collected data on the rate of DTs in revision and primary surgery. ${ }^{11}$ Studies generally scored high in selection and outcome criteria on the NewcastleOttawa quality assessment scale (Table 2) because all of the risk factors were related to the baseline characteristics of participants.

\section{The Incidence of Accidental DTs}

Based on all of the studies included, the overall pooled proportion of DTs in the spine was 0.058 (95\% confidence interval [CI] 0.044-0.073), corresponding to an incidence of $5.8 \%$ (95\% CI 4.4-7.3). The overall proportion in the lumbar spine was higher than the overall average, $0.061 \quad(95 \%$ CI 0.052-0.071) based on 17 studies. The overall proportion in the cervical spine was 0.017 (95\% CI $0.009-0.027)$ based on 5 studies, and the overall proportion in the thoracic spine was 0.043 (95\% CI 0.023-0.069) based on 4 studies.

\section{Risk Factors}

\section{Age}

Sixteen studies reported data on the age of patients (Table 3). Two studies ${ }^{18,29}$ categorized their patients based on diagnosis. The data for the subgroups from these two studies were entered independently in the meta-analysis calculation but were also subsequently pooled and entered in a separate sensitivity analysis. There was an overall weighted mean difference of 3.04 years $(95 \%$ CI $2.49-3.6, P$
$<.0001$ ) (ie, patients who sustained DTs were older [Figure 1]). The results remained the same following sensitivity analysis after pooling the data from the subgroups of patients from the 2 studies by Yoshihara et $\mathrm{al}^{18}$ and Stromqvist et $\mathrm{al}^{29}$ (Figure 2).

\section{Sex}

Eighteen studies reported data on the number of males and females in both groups (Table 3). The overall pooled proportion of DTs in males and females was the same, 0.06 (95\% CI $0.040-0.074)$ and 0.06 (95\% CI 0.041-0.076), respectively. Hence, the overall effect of sex on DTs was not significant, with an overall odds ratio of 1.04 (95\% CI $0.093-$ $1.15, P=.52$ ) of sustaining DTs in females (Figure 3).

\section{Diagnosis (Lumbar Stenosis versus Disc Herniation)}

Ten studies provided details for the underlying diagnosis. The pooled proportion of DTs in lumbar stenosis was more than double that of discectomy, 0.055 (95\% CI $0.034-0.081)$ and 0.027 (95\% CI $0.017-0.040)$, respectively. Therefore, DTs in lumbar stenosis surgery were overall twice as likely to occur with an overall odds ratio of 2.03 (95\% CI $1.50-2.75, P<.00001)$ relative to discectomy (Figure 4).

\section{Revision Surgery}

Thirteen studies provided data on revision surgery. The pooled adjusted proportion of DTs in revision surgery was more than double that in primary surgery, 0.118 (95\% CI $0.072-0.175)$ and 0.054 (95\% CI 0.031-0.083), respectively. Therefore, direct comparison revealed that DTs were twice as likely to occur in revision surgery, with an odds ratio of $2.28(95 \%$ CI $1.84-2.83, P<.0001)$ (Figure $5)$.

\section{Diabetes}

Ten studies provided data on diabetes. The rate of DTs in diabetic and nondiabetic patients differed significantly among the studies, but there was only a small difference in the overall pooled proportion of DTs in diabetic and nondiabetic patients, 0.068 (95\% CI $0.043-0.098)$ and 0.056 (95\% CI 0.034 0.082), respectively. In direct comparison, there was an overall odds ratio of 1.40 , barely reaching statistical significance (95\% CI 1.01-1.93, $P=.04$ ) (Figure 6). 


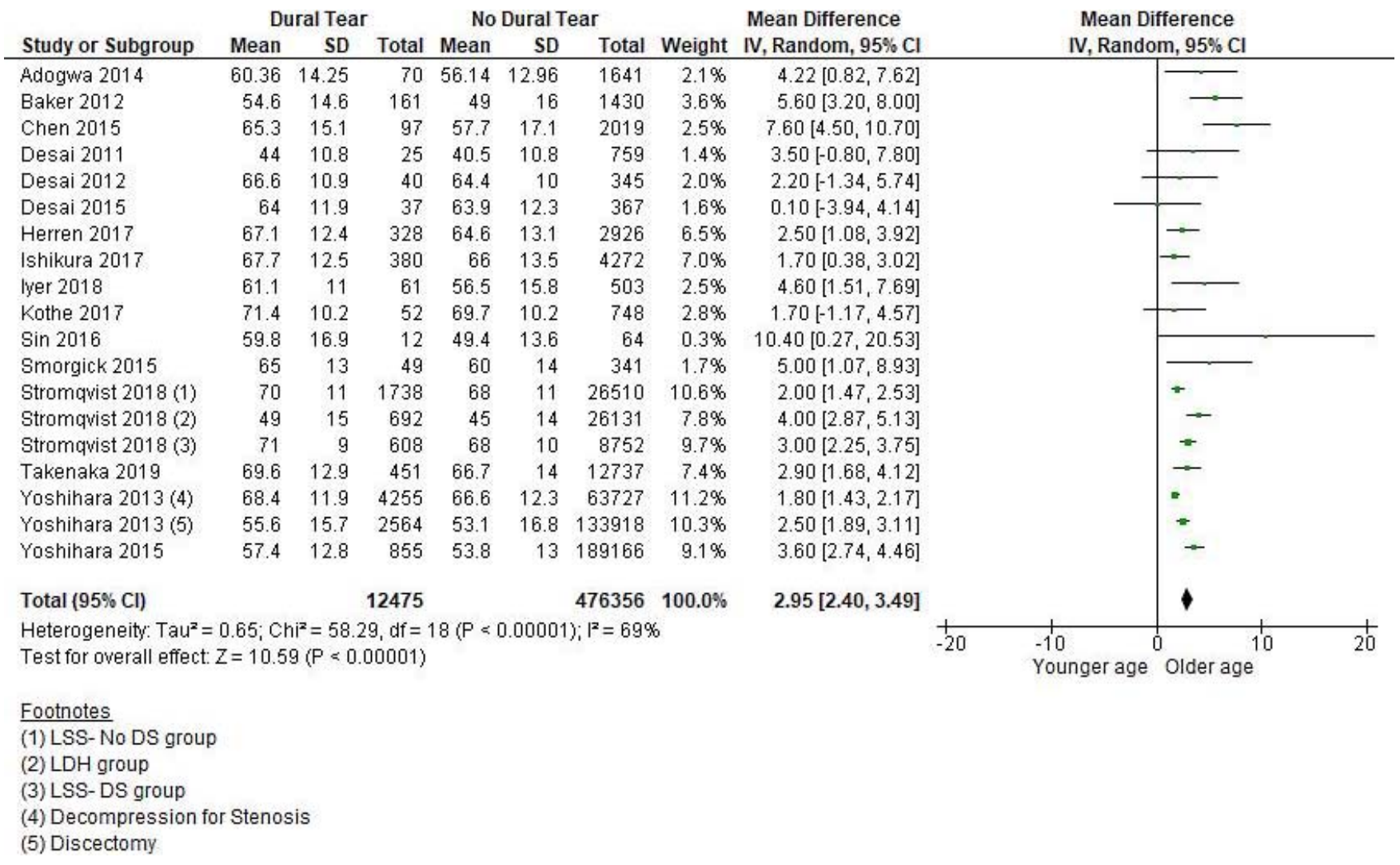

Figure 2. Forest plot depicting the overall difference in age between patients with and without dural tears. Data for the different categories from Stromqvist et al ${ }^{29}$ and Yoshihara et $\mathrm{al}^{21}$ were entered separately. DS, degenerative spondylolisthesis; LDH, lumbar disc herniation; LSS, lumbar spine stenosis.

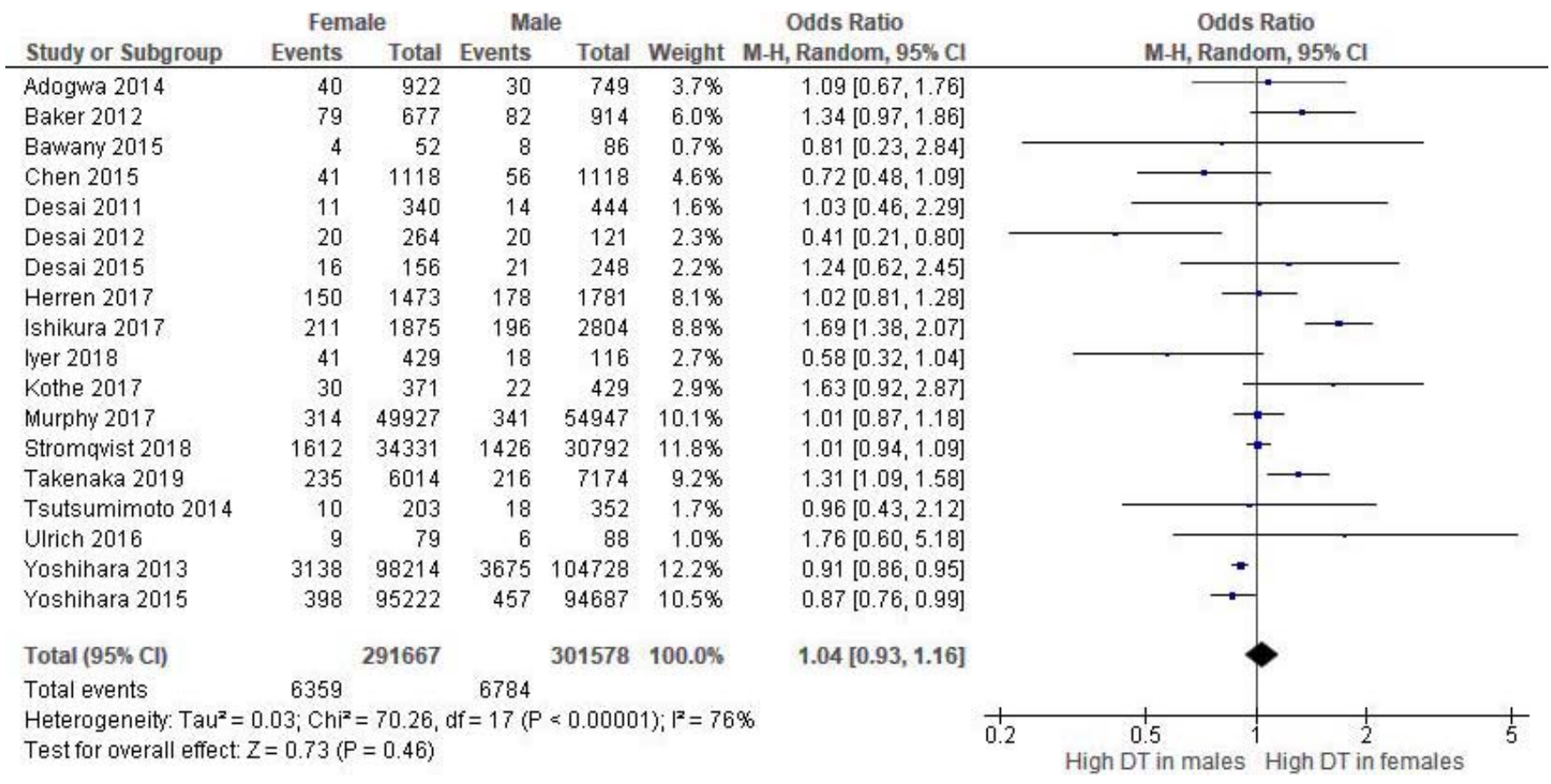

Figure 3. The overall odds ratios of DTs in females compared with males. DT, dural tear. 


\begin{tabular}{|c|c|c|c|c|c|c|c|c|c|c|}
\hline \multirow[b]{2}{*}{ Study or Subgroup } & \multicolumn{2}{|c|}{ Stenosis(decompression) } & \multicolumn{2}{|c|}{ Disc Herniation discectom } & \multirow[b]{2}{*}{ Weight } & \multirow{2}{*}{$\begin{array}{c}\text { Odds Ratio } \\
\text { M-H, Random, } 95 \% \mathrm{Cl}\end{array}$} & \multirow{2}{*}{\multicolumn{3}{|c|}{$\begin{array}{c}\text { Odds Ratio } \\
\text { M-H, Random, } 95 \% \mathrm{Cl}\end{array}$}} & \\
\hline & Events & Total & Events & Total & & & & & & \\
\hline Chen 2015 & 76 & 1176 & 34 & 637 & $10.0 \%$ & $1.23[0.81,1.86]$ & & ( & ? & \\
\hline Desai $2011 / 15$ (1) & 37 & 409 & 25 & 799 & $9.0 \%$ & $3.08[1.83,5.19]$ & & & & \\
\hline Smorgick 2015 & 49 & 392 & 6 & 131 & $6.1 \%$ & $2.98[1.24,7.12]$ & & & & \\
\hline Stromqvist 2018 & 1738 & 28248 & 692 & 26823 & $12.3 \%$ & $2.48[2.26,2.71]$ & & & & $\rightarrow$ \\
\hline Tafazal 2005 & 48 & 571 & 45 & 978 & $10.0 \%$ & $1.90[1.25,2.90]$ & & & & \\
\hline Takenaka 2019 & 231 & 6064 & 82 & 2735 & $11.4 \%$ & $1.28[0.99,1.66]$ & & & $\longrightarrow$ & \\
\hline Tsutsumimoto 2014 & 7 & 93 & 18 & 431 & $5.9 \%$ & $1.87[0.76,4.61]$ & & & & \\
\hline Williams et al 2011 & 273 & 16036 & 264 & 18008 & $11.9 \%$ & $1.16[0.98,1.38]$ & & & 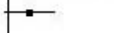 & \\
\hline Yoshihara 2013 & 4255 & 67982 & 2564 & 136482 & $12.4 \%$ & $3.49[3.32,3.67]$ & & & & 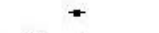 \\
\hline Yoshihara 2015 & 75 & 15573 & 101 & 55285 & $11.1 \%$ & $2.64[1.96,3.57]$ & & & & - \\
\hline Total $(95 \% \mathrm{Cl})$ & & 136544 & & 242309 & $100.0 \%$ & $2.03[1.50,2.75]$ & & & & \\
\hline Total events & 6789 & & 3831 & & & & & & & \\
\hline $\begin{array}{l}\text { Heterogeneity: } \mathrm{Tau}^{2}= \\
\text { Test for overall effect: }\end{array}$ & $\begin{array}{l}0.19 ; \mathrm{Chi}^{2}=235 . \\
=4.61(\mathrm{P}<0.00\end{array}$ & If $=9(\mathrm{P}<$ & $0.00001) ;\left.\right|^{2}=96$ & & & & 0.2 & ${ }^{0.5}$ discectomy & 1 High DTin & $\begin{array}{c}5 \\
\text { lumbar stenosis }\end{array}$ \\
\hline
\end{tabular}

Figure 4. The odds ratio of sustaining DTs in lumbar decompression surgery versus discectomy. Desai et al 2011 (study on discectomy) ${ }^{14}$ and Desai et al 2015 (study on lumbar decompression) ${ }^{23}$ were entered as a single study as they were published from the same unit. DT, dural tear.

\section{$B M I$}

The overall weighted BMI mean difference in patients with and without DTs (in 8 studies) was not statistically significant, $-0.45(95 \%$ CI $-1.43-$ $0.54, P=.38$ ) (Figure 7). Categorizing patients into obese $(\mathrm{BMI} \geq 30)$ and nonobese $(\mathrm{BMI}<30)$ groups (in 6 studies) also did not show any significant difference, with an odds ratio of 1.14 (95\% CI $0.97-$ $1.35, P=.12)$; the proportion of DTs in obese and nonobese patients was 0.052 (95\% CI $0.027-0.083)$ and $0.036(95 \%$ CI $0.016-0.063)$, respectively (Figure 8).

\section{Heterogeneity}

The level of heterogeneity is reported with each forest plot. There was a high level of heterogeneity for all risk factors. Heterogeneity did not improve when excluding (or including) studies with similar characteristics, similar scores, or relate to the same region of the spine. Sensitivity analysis by excluding one study at a time for each risk factor did not lower the heterogeneity and did not identify a single study accountable for most of the heterogeneity. Heterogeneity only improved after excluding several studies for each risk factor, but the studies excluded

\begin{tabular}{|c|c|c|c|c|c|c|c|c|c|c|}
\hline \multirow[b]{2}{*}{ Study or Subgroup } & \multicolumn{2}{|c|}{ Previous Surgery } & \multicolumn{2}{|c|}{ Primary surgery } & \multicolumn{2}{|r|}{ Odds Ratio } & \multirow{2}{*}{\multicolumn{4}{|c|}{$\begin{array}{l}\text { Odds Ratio } \\
\text { M-H, Random, } 95 \% \mathrm{Cl}\end{array}$}} \\
\hline & Events & Total & Events & Total & Weight & M-H, Random, 95\% Cl & & & & \\
\hline Baker 2012 & 62 & 285 & 99 & 1306 & $9.6 \%$ & $3.39[2.39,4.80]$ & & & $\longrightarrow$ & \\
\hline Chen 2015 (1) & 15 & 89 & 82 & 2027 & $6.6 \%$ & $4.81[2.65,8.74]$ & & & & \\
\hline Herren 2017 (2) & 50 & 343 & 278 & 2911 & $9.9 \%$ & $1.62[1.17,2.24]$ & & & $\rightarrow$ & \\
\hline Ishikura 2017 & 87 & 578 & 293 & 3987 & $10.7 \%$ & $2.23[1.73,2.89]$ & & & & \\
\hline lyer 2018 & 12 & 90 & 49 & 474 & $5.9 \%$ & $1.33[0.68,2.62]$ & & & & \\
\hline Kothe 2017 & 26 & 377 & 26 & 423 & $7.0 \%$ & $1.13[0.64,1.98]$ & & & & \\
\hline Lotfinia 2012 & 18 & 96 & 64 & 1018 & $6.9 \%$ & $3.44[1.94,6.09]$ & & & & \\
\hline McMahon 2012 & 23 & 352 & 81 & 2648 & $8.0 \%$ & $2.22[1.37,3.57]$ & & & & \\
\hline Smorgick 2015 (3) & 29 & 116 & 20 & 276 & $6.4 \%$ & $4.27[2.30,7.93]$ & & & & \\
\hline Stromqvist 2018 & 720 & 10554 & 2318 & 53877 & $12.2 \%$ & $1.63[1.49,1.78]$ & & & + & \\
\hline Tafazal 2005 & 14 & 106 & 31 & 872 & $5.9 \%$ & $4.13[2.12,8.04]$ & & & & \\
\hline Tsutsumimoto 2014 (4) & 0 & 6 & 28 & 549 & $0.6 \%$ & $1.41[0.08,25.61]$ & & & & \\
\hline Yoshihara 2015 & 52 & 7885 & 803 & 182136 & $10.4 \%$ & $1.50[1.13,1.99]$ & & & $\rightarrow$ & \\
\hline Total $(95 \% \mathrm{Cl})$ & & 20877 & & 252504 & $100.0 \%$ & $2.25[1.79,2.81]$ & & & & \\
\hline Total events & 1108 & & 4172 & & & & & & & \\
\hline \multicolumn{7}{|c|}{$\begin{array}{l}\text { Heterogeneity: } \operatorname{Tau}^{2}=0.11 ; \mathrm{Chi}^{2}=55.58, \mathrm{df}=12(\mathrm{P}<0.00001) ; \mathrm{I}^{2}=78 \% \\
\text { Test for overall effect: } Z=7.05(\mathrm{P}=0.00001)\end{array}$} & 0.05 & High DT in primary & High DT In revision & 20 \\
\hline \multicolumn{11}{|c|}{$\begin{array}{l}\text { Footnotes } \\
\text { (1) This study differentiated between prior surgery and revision surgery. used data on revision surgery } \\
\text { (2) Only data on revision suregry at the same level was used } \\
\text { (3) Data on laminectomy Vs revision laminectomy was used } \\
\text { (4) The study on microendoscopic lumbar surgery }\end{array}$} \\
\hline
\end{tabular}

Figure 5. Dural tears in primary versus revision spinal surgery. Overall rate of DTs in revision spinal surgery with an overall odds ratio of $2.28(P<.00001)$. DT, dural tear. 


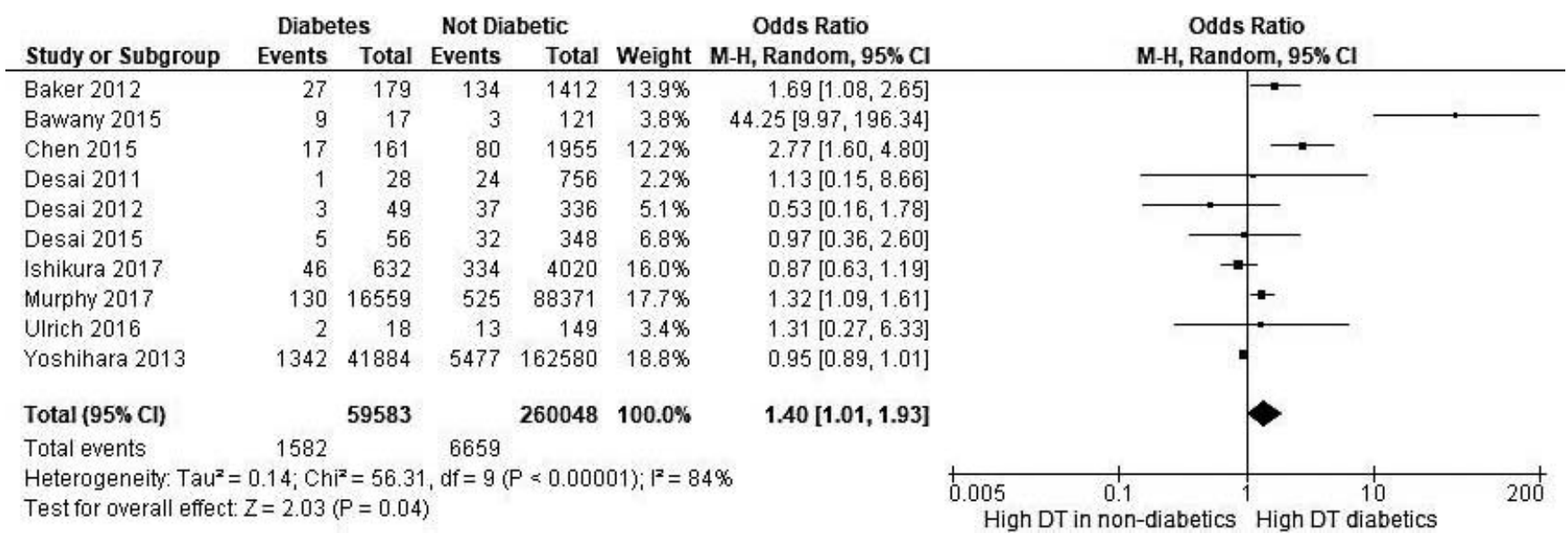

Figure 6. The overall odds of DTs in diabetic patients did not significantly differ from nondiabetic patients. DT, dural tear.

did not have any particular common factor. The plotted funnel plots did not reveal much asymmetry, and even after excluding the studies that appeared as outliers, heterogeneity did not significantly improve. Hence, it was decided to include all of the studies in our analysis in a random effect model regardless of the level of heterogeneity.

\section{DISCUSSION}

This systematic review and meta-analysis assessed six baseline characteristics of patients and their association with accidental DTs. We found that increasing age, revision surgery, and surgery for lumbar stenosis (as opposed to discectomy) were all associated with an increased rate of accidental DTs and, hence, could be considered as risk factors. Diabetes had a relatively weak association with DTs. Sex and high BMI (obesity) were not associated with an increased rate of DTs.

The overall incidence of accidental DTs significantly varied in the studies and ranged from $0.4 \%$ to $15.8 \%$. A main factor that may explain this variation was the size of the cohorts reported by each study (Figure 9). Centers with a high number of surgical procedures reported lower rates of DTs and vice versa. This is consistent with what has been reported in a large registry study from different centers across Europe. ${ }^{6}$

The increased rate of DTs in revision surgery has been consistently reported in the literature in multivariate analyses in several studies. ${ }^{3,5-7,16}$ This may be explained by factors such as scarring that predisposes to dural adhesions and loss of normal anatomical landmarks that increase the risk of DTs.

Similarly, age has also been shown to be an independent risk factor in both univariate and multivariate analyses. ${ }^{3,5-7,16,18,21,35}$ With advancing age, there is a reduction in the strength and elasticity of the dural sac, ${ }^{3}$ rendering the dura more delicate ${ }^{36}$ and redundant (because of shortening of the spine by degeneration ${ }^{18}$ ) and becomes easily trapped by the tongs of the Kerrison rongeur. ${ }^{18}$ Older patients are also more likely to have severe stenosis with thicker ligamentum flavum, ${ }^{18,35}$ and, therefore, one might consider lumbar stenosis and age as covari-

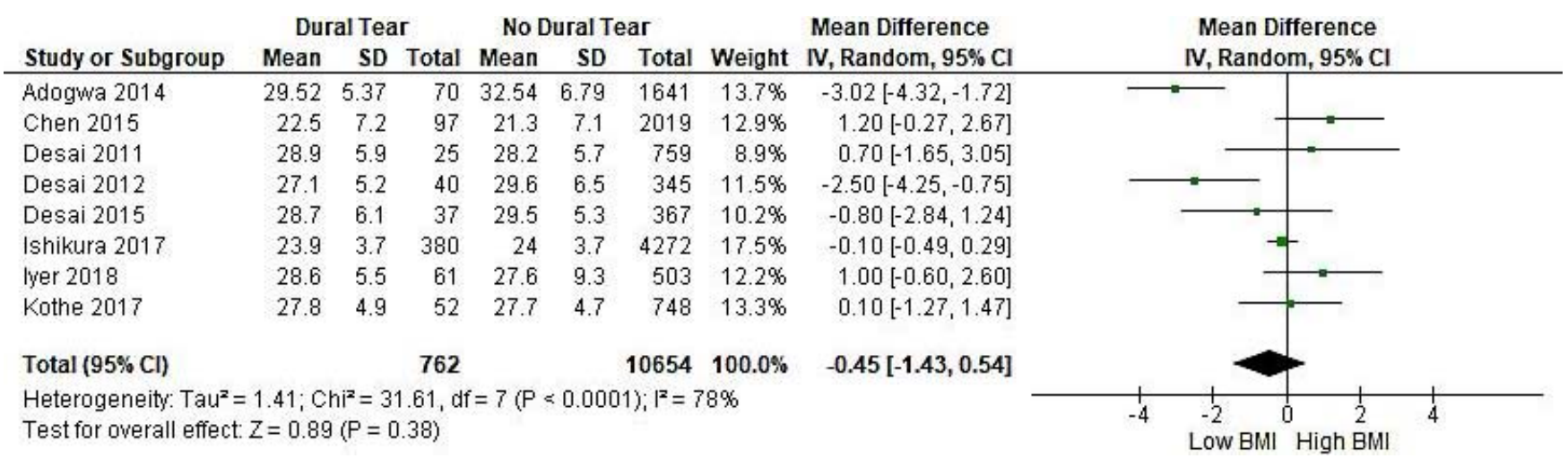

Figure 7. There was no overall difference in the mean body mass index (BMI) between patients with and without incidental DTs. DT, dural tear. 


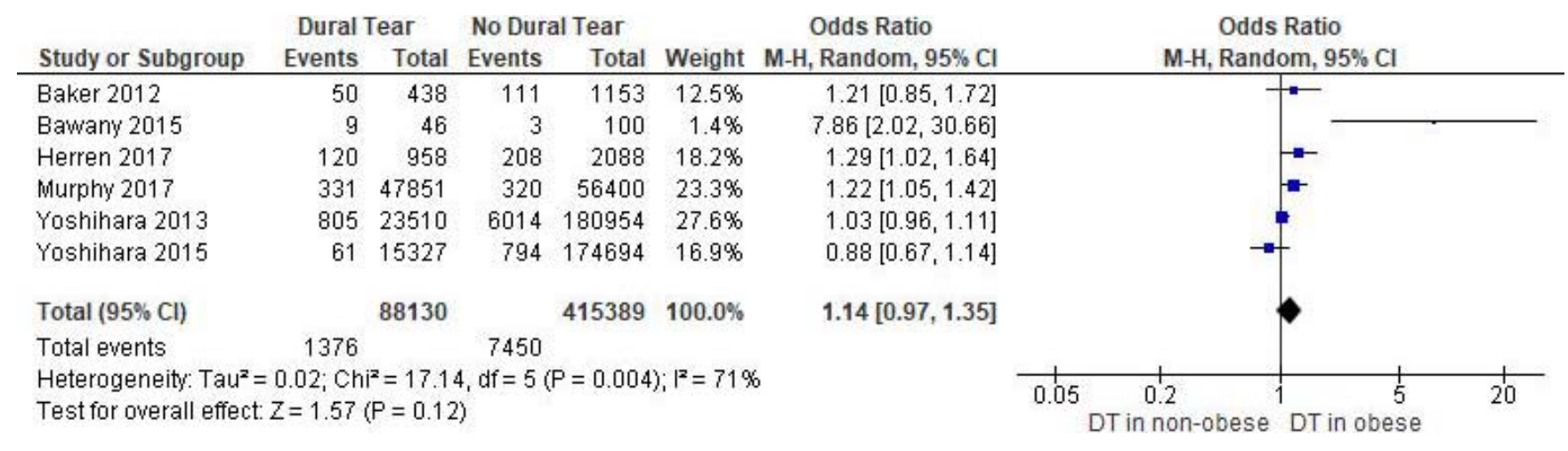

Figure 8. Forest plot with the overall odds of sustaining DTs in obese patients (body mass index [BMI] $>30$ ). No significant difference was observed between obese and nonobese patients. DT, dural tear.

ates (or confounding) factors rather than independent risk factors. This is because in severe stenosis, there is further thinning of the dura that is more likely to be adherent to the thickened ligamentum flavum, which further increases the risk of DTs. ${ }^{16}$ Furthermore, lumbar stenosis is mainly reported as a strong risk factor in univariate analysis and reached statistical significance in multivariate analysis in only a single study. ${ }^{7}$

Five of the studies reported diabetes as a significant risk factor on univariate analysis but failed to demonstrate the same significant results in multivariate analysis. ${ }^{7,16,18,25,37}$ In our analysis, the overall odds ratio was low (1.4), with a lower confidence interval of almost 1 (95\% CI 1.01-1.93), rendering it an almost insignificant risk factor. Although diabetes is commonly associated with other surgical complications, none of the studies have put forward a proposal explaining the association of diabetes with DTs. Similarly, 4 studies have associated obesity with DTs, ${ }^{6,18,25,37} 2$ on multivariate analysis, ${ }^{6,25}$ but no explanation for this has been proposed. We propose that obesity can potentially render surgery technically more challenging and hence more likely predispose the dura to injury. The proportion of DTs was slightly higher in obese than nonobese patients, but the overall odds ratio in our meta-analysis did not reach statistical significance. It was not possible to combine all of the studies into one meta-analysis for obesity as the studies with categorical data were separately analyzed from those with continuous data. This might have diluted the data and reduced the overall power to detect any significant difference.

Two studies reported that females are at an increased risk for DTs on multivariate analysis, ${ }^{18,21}$

Figure 9. The rate of dural tears (DTs) in relation to the sample size included in the studies. Studies with small sample sizes reported high variation in the rate of incidental DTs. Low incidences of DTs were reported by studies with larger sample sizes.

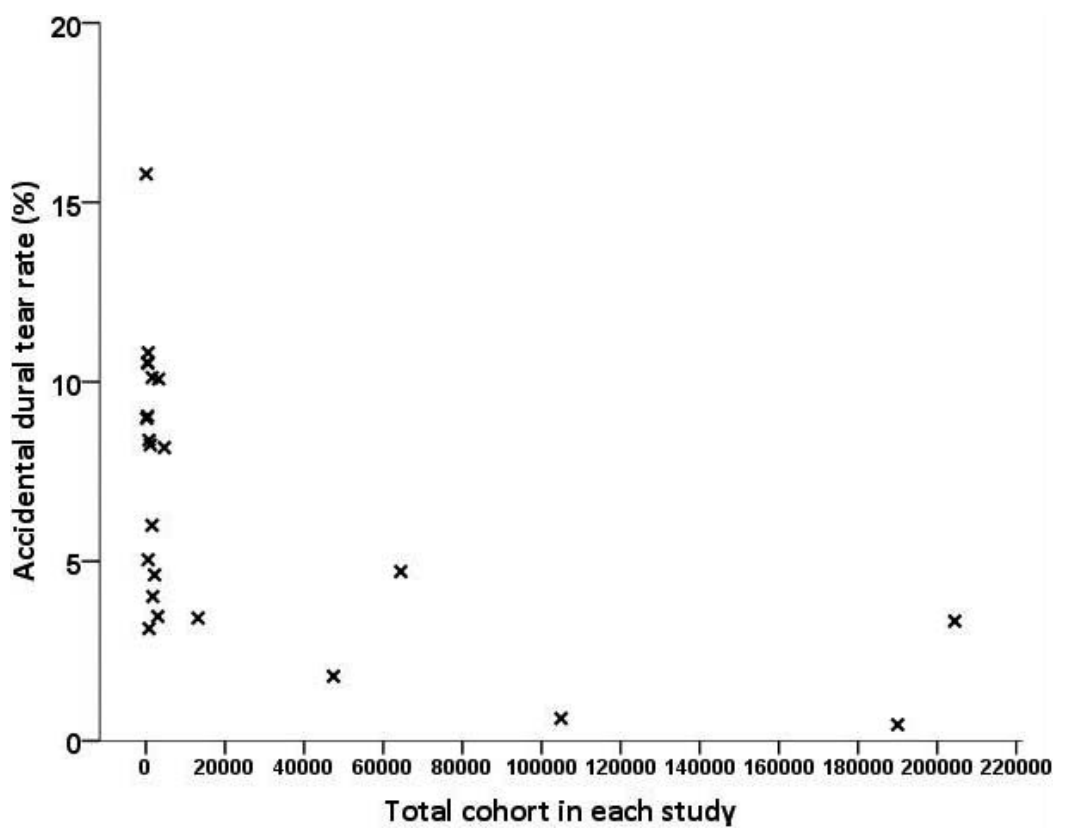


but we could not demonstrate this in this metaanalysis. It has been postulated that the dural sac in females is thinner than in males, ${ }^{38}$ and some have considered this as an explanation for the reported high risk of DTs in females. ${ }^{26}$ However, this difference in dural thickness is not statistically significant ${ }^{38,39}$ and, therefore, unlikely to account for the reported increased rate of DTs in females by some studies.

Data relating to risk factors were collected prospectively, and this bestows credibility to the data in these studies and to our meta-analysis results. Nevertheless, the quality of the studies included were all level 2 and 3 (cohort studies or case control) studies, and many were based on data from registries and hospital databases. This has resulted in publications with bigger sample sizes, conferring bigger weights to these studies, and heavily influenced the analysis for the overall effect. This could be one of the reasons why there was a high level of heterogeneity in the analysis. We have tried to ameliorate the impact of this by adopting a random effect model in our analysis, but we could not explain fully the reason for the high level of heterogeneity in our analysis.

In conclusion, revision surgery, age, and lumbar stenosis are risk factors for iatrogenic DTs in spinal surgery. These will need to be taken into consideration during the consenting process. The risk of diabetes was weak, and further studies are needed to address this.

\section{REFERENCES}

1. McMahon P, Dididze M, Levi AD. Incidental durotomy after spinal surgery: a prospective study in an academic institution. J Neurosurg Spine. 2012;17(1):30-36.

2. Kalevski SK, Peev NA, Haritonov DG. Incidental dural tears in lumbar decompressive surgery: incidence, causes, treatment, results. Asian J Neurosurg. 2010;5(1):54-59.

3. Stromqvist F, Jonsson B, Stromqvist B. Dural lesions in decompression for lumbar spinal stenosis: incidence, risk factors and effect on outcome. Eur Spine J. 2012;21(5):825-828.

4. Takahashi $\mathrm{Y}$, Sato $\mathrm{T}$, Hyodo $\mathrm{H}$, et al. Incidental durotomy during lumbar spine surgery: risk factors and anatomic locations. J Neurosurg Spine. 2013;18(2):165-169.

5. Du JY, Aichmair A, Kueper J, et al. Incidental durotomy during spinal surgery: a multivariate analysis for risk factors. Spine (Phila Pa 1976). 2014;39(22):E1339-E1345.

6. Herren C, Sobottke R, Mannion AF, et al. Incidental durotomy in decompression for lumbar spinal stenosis: incidence, risk factors and effect on outcomes in the Spine Tango registry. Eur Spine J. 2017;26(10):2483-2495.

7. Chen Z, Shao P, Sun Q, Zhao D. Risk factors for incidental durotomy during lumbar surgery: a retrospective study by multivariate analysis. Clin Neurol Neurosurg. 2015;130:101-104.

8. Hannallah D, Lee J, Khan M, Donaldson WF, Kang JD. Cerebrospinal fluid leaks following cervical spine surgery. $J$ Bone Joint Surg Am. 2008;90(5):1101-1105.

9. Alshameeri ZAF, Ahmed E, Jasani V. Clinical outcome of spine surgery complicated by accidental dural tears: metaanalysis of the literature. Global Spine J. 2021;11(3):400-409. doi: $10.1177 / 2192568220914876$

10. Alshameeri ZAF, El-Mubarak A, Kim E, Jasani V. A systematic review and meta-analysis on the management of accidental dural tears in spinal surgery: drowning in information but thirsty for a clear message. Eur Spine J. 2020;29(7):16711685.

11. Tafazal SI, Sell PJ. Incidental durotomy in lumbar spine surgery: incidence and management. Eur Spine J. 2005;14(3):287290.

12. Sin AH, Caldito G, Smith D, Rashidi M, Willis B, Nanda A. Predictive factors for dural tear and cerebrospinal fluid leakage in patients undergoing lumbar surgery. $J$ Neurosurg Spine. 2006;5(3):224-227.

13. Williams BJ, Sansur CA, Smith JS, et al. Incidence of unintended durotomy in spine surgery based on 108,478 cases. Neurosurgery. 2011;68(1):117-123; discussion 123-114.

14. Desai A, Ball PA, Bekelis K, et al. Outcomes after incidental durotomy during first-time lumbar discectomy. $J$ Neurosurg Spine. 2011;14(5):647-653.

15. Lotfinia I, Sayyahmelli S. Incidental durotomy during lumbar spine surgery. Neurosurg Q. 2012;22(2):105-112.

16. Baker GA, Cizik AM, Bransford RJ, et al. Risk factors for unintended durotomy during spine surgery: a multivariate analysis. Spine J. 2012;12(2):121-126.

17. Desai A, Ball PA, Bekelis K, et al. Surgery for lumbar degenerative spondylolisthesis in Spine Patient Outcomes Research Trial: does incidental durotomy affect outcome? Spine (Phila Pa 1976). 2012;37(5):406-413.

18. Yoshihara H, Yoneoka D. Incidental dural tear in lumbar spinal decompression and discectomy: analysis of a nationwide database. Arch Orthop Trauma Surg. 2013;133(11):1501-1508.

19. Tsutsumimoto T, Yui M, Uehara M, Ohta H, Kosaku $\mathrm{H}$, Misawa $\mathrm{H}$. A prospective study of the incidence and outcomes of incidental dural tears in microendoscopic lumbar decompressive surgery. Bone Joint J. 2014;96-B(5):641-645.

20. Adogwa O, Huang MI, Thompson PM, et al. No difference in postoperative complications, pain, and functional outcomes up to 2 years after incidental durotomy in lumbar spinal fusion: a prospective, multi-institutional, propensitymatched analysis of 1,741 patients. Spine J. 2014;14(9):18281834.

21. Yoshihara H, Yoneoka D. Incidental dural tear in cervical spine surgery: analysis of a nationwide database. $J$ Spinal Disord Tech. 2015;28(1):19-24.

22. Smorgick Y, Baker KC, Herkowitz H, et al. Predisposing factors for dural tear in patients undergoing lumbar spine surgery. J Neurosurg Spine. 2015;22(5):483-486.

23. Desai A, Ball PA, Bekelis K, et al. SPORT: does incidental durotomy affect longterm outcomes in cases of spinal stenosis? Neurosurgery. 2015;76(Suppl 1):S57-S63; discussion S63.

24. Ulrich NH, Burgstaller JM, Brunner F, et al. The impact of incidental durotomy on the outcome of decompression surgery in degenerative lumbar spinal canal stenosis: analysis of 
the Lumbar Spinal Outcome Study (LSOS) data-a Swiss prospective multi-center cohort study. BMC Musculoskelet Disord. 2016;17:170. doi:10.1186/s12891-016-1022-y

25. Murphy ME, Kerezoudis P, Alvi MA, et al. Risk factors for dural tears: a study of elective spine surgery. Neurol Res. 2017:39(2):97-106.

26. Ishikura $\mathrm{H}$, Ogihara $\mathrm{S}, \mathrm{Oka} \mathrm{H}$, et al. Risk factors for incidental durotomy during posterior open spine surgery for degenerative diseases in adults: a multicenter observational study. PLoS One. 2017;12(11):e0188038. doi:10.1371/journal. pone. 0188038

27. Kothe R, Quante M, Engler N, et al. The effect of incidental dural lesions on outcome after decompression surgery for lumbar spinal stenosis: results of a multi-center study with 800 patients. Eur Spine J. 2017;26(10):2504-2511.

28. Iyer S, Klineberg EO, Zebala LP, et al. Dural tears in adult deformity surgery: incidence, risk factors, and outcomes. Global Spine J. 2018;8(1):25-31.

29. Stromqvist F, Sigmundsson FG, Stromqvist B, Jonsson B, Karlsson MK. Incidental durotomy in degenerative lumbar spine surgery - a register study of 64,431 operations. Spine $J$. 2019;19(4):624-630. doi:10.1016/j.spinee.2018.08.012

30. Takenaka S, Makino T, Sakai Y, et al. Dural tear is associated with an increased rate of other perioperative complications in primary lumbar spine surgery for degenerative diseases. Medicine (Baltimore). 2019;98(1):e13970. doi:10.1097/ MD.0000000000013970

31. Wells GA, Shea B, O'Connell D, et al. The NewcastleOttawa Scale (NOS) for assessing the quality of nonrandomised studies in meta-analyses. http://www.ohri.ca/programs/clinical_ epidemiology/oxford.asp. Accessed August 27, 2019.

32. World Health Organization. Obesity. https://www.who. int/topics/obesity/en/. Accessed August 27, 2019.

33. Barendregt JJ, Doi SA, Lee YY, Norman RE, Vos T. Meta-analysis of prevalence. J Epidemiol Community Health. 2013;67(11):974-978.

34. Murad MH, Sultan S, Haffar S, Bazerbachi F.
Methodological quality and synthesis of case series and case reports. BMJ Evid Based Med. 2018;23(2):60-63.

35. Buck JS, Yoon ST. The incidence of durotomy and its clinical and economic impact in primary, short-segment lumbar fusion: an analysis of 17,232 cases. Spine (Phila Pa 1976). 2015;40(18):1444-1450.

36. Guerin P, El Fegoun AB, Obeid I, et al. Incidental durotomy during spine surgery: incidence, management and complications. A retrospective review. Injury. 2012;43(4):397401.

37. Bawany FI, Emaduddin M, Shahid M, Hussain M, Yousuful Islam M, Khan MS. Incidence of pinhole type durotomy and subsequent cerebrospinal fluid leakage following simple laminectomy. Asian Spine J. 2015;9(4):529-534.

38. Hong JY, Suh SW, Park SY, et al. Analysis of dural sac thickness in human spine - cadaver study with confocal infrared laser microscope. Spine J. 2011;11(12):1121-1127.

39. Kwon S, Suh SW, Kim D, et al. Analysis of dural sac thickness in the human cervical spine. Anat Sci Int. 2018;93(2):284-290.

Disclosures and COl: None declared.

Corresponding Author: Zeiad A.F. Alshameeri, University Hospital of North Midlands, Royal Stoke University Hospital, Newcastle Rd, Stoke-onTrent, ST4 6QG, UK. Phone: 00441782715444; Email: zeiad@doctors.org.uk.

Published 1 June 2021

This manuscript is generously published free of charge by ISASS, the International Society for the Advancement of Spine Surgery. Copyright (c) 2021 ISASS. To see more or order reprints or permissions, see http://ijssurgery.com. 